\title{
Clinical and demographic profile of chromoblastomycosis in a referral service in the midwest of São Paulo state (Brazil)*
}

\author{
Gabriela Franco Marques ${ }^{1}$ \\ Paula Yoshiko Masuda ${ }^{1}$ \\ Juliana Martins Prazeres Sousa ${ }^{1}$ \\ DOI: http://dx.doi.org/10.1590/abd1806-4841.20153252
}

Jaison Antônio Barreto ${ }^{1}$

Patrick Alexander Wachholz ${ }^{2}$

\begin{abstract}
Chromoblastomycosis is one of the most frequent deep mycoses found in rural populations. This crosssectional, retrospective and descriptive study was conducted with cases of chromoblastomycosis diagnosed throughout 20 years. A higher prevalence was observed among White male rural workers, with an average age of 59.69 years. Median time between onset of symptoms and diagnosis was 156 months. Lesions were predominantly located on the lower limbs; $34 \%$ of cases reported previous trauma. The most common associated symptoms were itching, pain and burning sensation. Mycological examination was positive in $91 \%$ of cases and Fonsecaea pedrosoi was the most prevalent etiologic agent.
\end{abstract}

Keywords: Chromoblastomycosis; Epidemiology; Fungi; Mycoses

Chromoblastomycosis is a chronic granulomatous infection of the skin caused by a dematiaceous fungi. It has worldwide distribution and predilection for tropical and temperate climates. ${ }^{1,2}$ The infection is detected in all regions of Brazil and has an estimated prevalence of 1/196 thousand inhabitants. ${ }^{3}$ Infection occurs by accidental contact of the fungus with humans, which is favored by agricultural activities and denotes the occupational nature of the disease., ${ }^{4,5}$

This study proposed to evaluate the demographic and clinical characteristics, direct mycological examination and culture results of patients with chromoblastomycosis, assessed over a period of 20 years in a dermatology referral service in the midwestern region of the state of São Paulo (Brazil).

This was a cross-sectional, retrospective, descriptive study. We carried out secondary data collection from medical records in the period between 1991 and 2011. We selected all records of patients with a clinical diagnosis of chromoblastomycosis, according to their registration in the medical file system of the institution - which was in accordance with the international classification of diseases (ICD-10). Of these, only those cases of chromoblastomycosis which were confirmed by histopathology were included in the study. Total sample was comprised of 62 patients.

The variables of each patient were recorded on forms, individually reviewed by one of the authors to ensure that no data collection errors had occurred, and transferred to Microsoft Excel ${ }^{\circledR}$. Data analysis was performed with Statistica software $10.0^{\circledR}$ using descriptive statistics. The symmetry of the continuous variables was analyzed using the Kolmogorov-Smirnov test, and presented by measures of central tendency. Categorical variables were presented as percentage of occurrence.

We identified a predominance of chromoblastomycosis in white ethnic groups $(79.36 \%)$, male $(87.30 \%)$ rural workers $(57.14 \%)$, with a mean age of $59.69( \pm 12.95)$ years, coming from other states $(61.91 \%)$ than that of the institution, and who resided in rural areas $(77.77 \%)$. The median time in months between the onset of the lesion and diagnosis was 156 months (84-240).

Lesions affected more than one anatomic site in only $14.28 \%(n=9)$ of patients. The lower limbs were affected in $54.05 \%(n=40)$ of cases, and the upper limbs in $33.78 \%(n=25)$ of cases. The medical records of twenty-two patients (34.92\%) showed reports of previous trauma. The most frequently associated symptoms individually reported were: pruritus $(41.56 \%, \mathrm{n}=32)$, pain $(18.18 \%, \mathrm{n}=14)$ and burning sensation $(10.39 \%, n=8)$. Mycological examination was positive in $66.66 \%(n=42)$ of cases. Fonsecaea pedrosoi were the most prevalent etiologic agents (73.01\%). Four cases showed a positive culture for Cladophialophora carrioni.

\footnotetext{
Received on 06.11.2013.

Approved by the Advisory Board and accepted for publication on 28.11.2013.

Study conducted at Lauro de Souza Lima Institute (ILSL) - Bauru (SP), Brazil.

Conflict of interest: None

Financial Support: None

Lauro de Souza Lima Institute (ILSL) - Bauru (SP), Brazil.

Universidade Estadual Paulista Júlio de Mesquita Filho (UNESP), Botucatu (SP), Brazil. 
The socio-demographic findings for this sample are consistent with those described in the literature (Table 1) ${ }^{6-10}$ The prevalence was higher in male rural workers living in non-urbanized areas.This predominance was expected because agricultural activities favors contact between host and fungus.The latter penetrates the skin by traumatic implantation, especially in areas not covered by clothing. The most exposed regions of the body are the upper and lower limbs, which reinforces our findings. ${ }^{3,6}$

Associated symptoms were pruritus, pain and burning paresthesia. Pruritus is usually not a symptom described in most studies. Nevertheless, like pain and burning, it can be explained due to irritation of superficial nerve endings by the intense local granulomatous and suppurative process. A previous trauma history was rarely reported, however, it is plausible, since in most cases the penetration of the agent occurs by micro-traumas, which are undetectable by the host. ${ }^{10}$

The average age at onset of lesions is consistent with other studies.Most cases were aged 60 years or over, an age at which many infectious diseases related to decreased cellular immunity are found. ${ }^{7,9}$ Although observed in this study, there is no description in the literature stating that the white race is predominantly affected.

With regard to the geographical distribution, it is known that the disease is endemic in Rio Grande do Sul, São Paulo, Rio de Janeiro, Minas Gerais and in the states of the Amazon region. ${ }^{6,7}$ In the cases analyzed here, most subjects were coming from other states of

TABLE 1: Socio-demographic characteristics of the studied sample $(n=63)$. Lauro de Souza Lima Institute(ILSL), Bauru - SP (Brazil)

\begin{tabular}{|c|c|c|c|}
\hline Characteristic & Groups & $\mathbf{n}$ & Percentage \\
\hline \multicolumn{4}{|l|}{ Age } \\
\hline \multirow[t]{3}{*}{ (groups) } & UP TO 45YEARS & 9 & 14.30 \\
\hline & 45 - 59 YEARS & 22 & 34.90 \\
\hline & 60 YEARS OR OVER & 32 & 50.80 \\
\hline \multirow[t]{2}{*}{ Gender } & MALE & 55 & 87.30 \\
\hline & FEMALE & 8 & 12.69 \\
\hline \multirow[t]{4}{*}{ Race } & WHITE & 50 & 79.36 \\
\hline & BROWN & 6 & 9.52 \\
\hline & BLACK & 4 & 6.34 \\
\hline & NOT DESCRIBED & 3 & 4.76 \\
\hline \multirow[t]{5}{*}{ Profession } & RURAL WORKER & 36 & 57.14 \\
\hline & RUBBER TAPPER & 4 & 6.34 \\
\hline & MASON & 1 & 1.58 \\
\hline & HOUSEMAID & 5 & 7.93 \\
\hline & OTHERS & 17 & 27.01 \\
\hline \multirow[t]{6}{*}{ Provenance } & SP & 24 & 38.09 \\
\hline & $\mathrm{AC}$ & 13 & 20.63 \\
\hline & $\mathrm{MT}$ & 7 & 11.11 \\
\hline & $\mathrm{RO}$ & 5 & 7.93 \\
\hline & MS & 4 & 6.34 \\
\hline & OTHERS & 10 & 15.90 \\
\hline \multirow[t]{2}{*}{ Area of residence } & COUNTRY & 49 & 77.77 \\
\hline & METROPOLITAN & 14 & 22.22 \\
\hline
\end{tabular}

TABLE 2: Clinical and laboratory profileof the studied sample(n=63). Lauro de Souza Lima Institute(ILSL), Bauru - SP (Brazil))

\begin{tabular}{|c|c|c|c|}
\hline Clinical and & Groups & $\mathbf{N}$ & Percentage \\
\hline \multicolumn{4}{|l|}{$\begin{array}{l}\text { laboratory } \\
\text { characteristics }\end{array}$} \\
\hline \multirow{2}{*}{$\begin{array}{l}\text { Distribution } \\
\text { of lesions }\end{array}$} & ONE SITE & 54 & 85.71 \\
\hline & MORE THAN ONE SITE & 9 & 14.28 \\
\hline \multirow{2}{*}{$\begin{array}{l}\text { Confirmed report } \\
\text { of previous trauma }\end{array}$} & YES & 22 & 34.92 \\
\hline & NO & 41 & 65.07 \\
\hline \multirow{6}{*}{$\begin{array}{l}\text { Site affected } \\
\text { by lesions }\end{array}$} & INFERIOR LIMBS & 40 & 54.05 \\
\hline & SUPERIOR LIMBS & 25 & 33.78 \\
\hline & GLUTEAL REGION & 3 & 4.06 \\
\hline & FACE & 3 & 4.06 \\
\hline & DORSUM & 2 & 2.70 \\
\hline & NECK & 1 & 1.35 \\
\hline \multirow{4}{*}{$\begin{array}{l}\text { Symptoms } \\
\text { associated with } \\
\text { the lesions }\end{array}$} & PRURITUS & 32 & 41.56 \\
\hline & NONE & 23 & 29.87 \\
\hline & PAIN & 14 & 18.18 \\
\hline & BURNING & 8 & 10.39 \\
\hline \multirow[t]{4}{*}{ Culture results } & NEGAtive & 7 & 11.11 \\
\hline & FONSECAEA PEDROSOI & 46 & 73.01 \\
\hline & NOT CARRIED OUT & 6 & 9.52 \\
\hline & CLADOPHIALOPHORA CARRIONII & 4 & 6.34 \\
\hline \multirow{3}{*}{$\begin{array}{l}\text { Direct mycological } \\
\text { examination }\end{array}$} & Negative & 4 & 6.34 \\
\hline & Positive & 42 & 66.66 \\
\hline & NOT CARRIED OUT & 17 & 26.98 \\
\hline
\end{tabular}

the Brazil, which possibly indicates the difficulty of diagnosis in some regions of the country. Given the fact that the study was conducted in a regional referral center, it is important to highlight that there is a potential selection bias, and the authors acknowledge this as a limitation of this study.

In the evaluation of clinical data, we found that the average time between the onset of the lesion and diagnosis was higher than that reported in other studies, probably because the subjects of this study are a low-income, poorly enlightened population who has difficult access to health services. ${ }^{6,7}$

The diagnosis of chromoblastomycosis is made by direct mycological examination, isolation of the fungus in a suitable culture medium and anatomopathological examination. ${ }^{1,2,4}$ The latter reveals pseudoepitheliomatous hyperplasia, suppurative and granulomatous inflammatory response, muriform cells and other fungal structures. ${ }^{9}$ Direct mycological examination is extremely useful, easily carried out, has high sensitivity and specificity.It was positive in $91 \%$ of the studied cases, and sclerotic or muriform bodieswere observed. Fonsecaea pedrosoi were the etiologic agents most commonly isolated in culture, which is in agreement with the literature (Table 2) ${ }^{6,7,8,10}$ 
We conclude that chromoblastomycosis is a deep mycosis of relevance to public health in the country. Knowledge of epidemiological and clinical characteristics of the affected population is needed. The findings of this study are consistent with the literature, except for the presence of pruritus, which was a frequent and important symptom found in the studied sample. Direct mycological examination is highly sensitive and specific. This diagnosis should always be considered in face of non-regressive pruritic lesion on the lower limbs, especially in male rural workers of advanced age.

\section{REFERENCES}

1. López Martínez R, Méndez Tovar LJ. Chromoblastomycosis. Clin Dermatol. 2007;25:188-94.

2. Torres-Guerrero E, Isa-Isa R, Isa M, Arenas R. Chromoblastomycosis. Clin Dermatol. 2012;30:403-8.

3. Ribeiro EL, Soares AJ, Ferreira WM, Cardoso CG, Naves PLF, Dias SMS Cromoblastomicose: doença presente na realidade populacional brasileira. Rev Bras Anal Clin. 2006;38:189-92

4. Queiroz-Telles F, Esterre P, Perez-Blanco M, Vitale RG, Salgado CG, Bonifaz A.Chromoblastomycosis: an overview of clinical manifestations, diagnosis and treatment. Med Mycol. 2009;47:3-15.

5. Ameen M. Chromoblastomycosis: clinical presentation and management. Clin Exp Dermatol. 2009;34:849-54.

6. Correia RT, Valente NY, Criado PR, Martins JE. Chromoblastomycosis: study of 27 cases and review of medical literature. An Bras Dermatol. 2010;85:448-54.

7. Pires CA, Xavier MB, Quaresma JA, Macedo GM, Sousa BR, Brito AC. Clinical, epidemiological and mycological report on 65 patients from the Eastern Amazon region with chromoblastomycosis. An Bras Dermatol. 2012;87:555-60.

8. Mouchalouat Mde F, Gutierrez Galhardo MC, Zancopé-Oliveira RM, Monteiro Fialho PC, de Oliveira Coelho JM, Silva Tavares PM, et al. Chromoblastomycosis: a clinical and molecular study of 18 cases in Rio de Janeiro, Brazil. Int J Dermatol. 2011;50:981-6.

9. Avelar-Pires C, Simoes-Quaresma JA, Moraes-de Macedo GM, Brasil-Xavier M, Cardoso-de Brito A. Revisiting the clinical and histopathological aspects of patients with chromoblastomycosis from the Brazilian Amazon region. Arch Med Res. 2013;44:302-6.

10. Chandran V, Sadanandan SM, Sobhanakumari K. Chromoblastomycosis in Kerala, India. Indian J Dermatol Venereol Leprol. 2012;78:728-33.

\author{
MAILING ADDRESS: \\ Gabriela Franco Marques \\ Rua Alves Guimarães 518 ap 136 - Pinheiros \\ 05419-000 - São Paulo - SP \\ Brazil \\ E-mail:gabriela_franco_@hotmail.com
}

How to cite this article: Marques GF, Barreto JA, Masuda PY, Wachholz PA, Sousa JMP. Clinical and demographic profile of chromoblastomycosis in a referral service in the midwest of São Paulo state (Brazil). An Bras Dermatol. 2015;90(1):140-2. 